\title{
Rol del Estado en el desarrollo de las actividades extractivas (2003-2015). El territorio de la soja, minería e hidrocarburos en Argentina
}

- Recepción: 03 de agosto de 2020 - Evaluación: 13 de mayo de 2021 - Aprobación: 10 de junio de 2021

Resumen: El presente artículo se propone analizar y comparar el papel desempeñado por el Estado en la planificación y en el acondicionamiento del territorio para el despliegue de actividades extractivas, y las tensiones de la puesta en marcha de la estrategia neodesarrollista en el contexto global de avance neoliberal. Se consideran como casos de análisis la actividad sojera en la provincia de Chaco, la minería metalífera a cielo abierto en Catamarca y el desarrollo de hidrocarburos no convencionales en la provincia de Neuquén, entre los años 2003 y 2015. Se revisan tanto el marco normativo como los proyectos y las obras realizadas para cada caso y desde los distintos niveles del Estado nacional, provincial y municipal, y se identifican continuidades y rupturas en la modalidad de intervención del Estado, tanto en su papel de mediador de intereses y demandas contrapuestas como a partir de la elaboración del marco normativo y la ejecución de infraestructuras. Entre los resultados y conclusiones, se destaca el protagonismo del Estado nacional en los procesos de acondicionamiento del territorio en articulación con los niveles provinciales, así como en la construcción de la agenda de proyectos. En este sentido, se observó que las intervenciones realizadas priorizaron las necesidades operativas de las actividades analizadas en infraestructuras para el desarrollo de las actividades extractivas y, en menor grado, las de las comunidades locales.

Palabras clave: Estado, ordenamiento territorial, gestión territorial, neoliberalismo.

Para citar: Schweitzer, M., Petrocelli, S., \& Scardino, M. (2021). Rol del Estado en el desarrollo de las actividades extractivas (2003-2015). El territorio de la soja, minería e hidrocarburos en Argentina. Perspectiva Geográfica, 26(2), 112-131. https://doi.org/10.19053/01233769.11548

Doctora en Arquitectura, Área Urbanismo, Universidad de Buenos Aires. Magíster en Planificación Urbana y Regional y Especialista en Planificación Urbana y Regional, Programa de Formación en Planificación Urbana y Regional, Facultad de Arquitectura, Diseño y Urbanismo, Universidad de Buenos Aires. Investigadora Independiente CONICET. Correo: marianaschweitzer@conicet.gov.ar. Orcid: https://orcid.org/0000-0002-8225-9993.

Especialista en Planificación Urbana y Regional, Programa de Formación en Planificación Urbana y Regional, Facultad de Arquitectura, Diseño y Urbanismo, Universidad de Buenos Aires. Becaria doctoral conicet. Correo: marisa.scardino@fadu.uba.ar. Orcid: https://orcid.org/0000-0001-5132-5102. 


\title{
Role of the State in the development of extractive activities (2003-2015). The territory of soybean, mining and hydrocarbons in Argentina
}

\begin{abstract}
This article aims to analyze and compare the role played by the State in the planning and conditioning of the territory for the deployment of extractive activities, and the tensions of the implementation of the neo-developmentalist strategy in the global context of neoliberal advance. Are considered as cases of analysis the soybean activity in the province of Chaco, the open-pit metalliferous mining in Catamarca and the development of unconventional hydrocarbons in the province of Neuquén, between 2003 and 2015. Both the regulatory framework and the projects and works carried out for each case and from the different levels of the national, provincial and municipal State are reviewed, and continuities and ruptures are identified in the modality of State intervention, both in its role as mediator of conflicting interests and demands and from the development of the regulatory framework and the execution of infrastructures. Among the results and conclusions, the protagonism of the national State stands out in the processes of territorial conditioning in articulation with the provincial levels, as well as in the construction of the project agenda. In this sense, it was observed that the interventions carried out prioritized the operational needs of the activities analyzed in infrastructure for the development of extractive activities and, to a lesser extent, those of the local communities.
\end{abstract}

Keywords: State, territorial ordering, territorial management, neoliberalism.

\section{Função do Estado no desenvolvimento das atividades extrativistas (2003-2015). O território da soja, mineração e hidrocarbonetos na Argentina}

\begin{abstract}
Resumo: O atual artigo tem como objetivo analisar e comparar o papel desempenhado pelo Estado no planejamento e no condicionamento do território para a implantação de atividades extrativistas, e as tensões da implementação da estratégia de neodesenvolvimento no contexto global de avanço neoliberal. Consideram-se como casos de análise a atividade referente à soja na província de Chaco, a mineração de metais a céu aberto em Catamarca e o desenvolvimento de hidrocarbonetos não convencionais na província de Neuquén, entre os anos de 2003 e 2015. Revisa-se tanto o enquadramento regulatório como os projetos e os trabalhos realizados para cada caso e a partir dos diferentes níveis do Estado, provincial e municipal, identificandose continuidades e rupturas na modalidade de intervenção do Estado, mesmo no seu papel de mediador de interesses e exigências contrapostas como a partir do desenvolvimento do quadro regulamentar e da implementação de infraestruturas. Entre os resultados e conclusões, destaca-se o protagonismo do Estado nos processos de condicionamento do território em coordenação com os níveis provinciais, bem como na construção da agenda de projetos. Neste sentido, observou-se que as intervenções realizadas priorizaram as necessidades operacionais das atividades analisadas em infraestruturas para o desenvolvimento das atividades extrativas e, em menor medida, das comunidades locais.
\end{abstract}

Palavras-chave: Estado, ordenamento territorial, gestão territorial, neoliberalismo. 


\section{Introducción}

La producción del territorio y el proceso de circulación y acumulación del capital son procesos que han estado históricamente vinculados entre sí (Harvey, 2005). El nuevo ordenamiento espacial, surgido con la nueva división internacional del trabajo que fue consolidándose a partir de finales del siglo pasado, condujo a demarcar un conjunto de espacios centrales, dedicados a las actividades de mando, y otros periféricos, destinados a la producción a gran escala o directamente vinculados a la extracción de bienes comunes. En esta configuración socioterritorial, los países latinoamericanos han quedado situados en los márgenes y, en algunos casos, continúan siendo avasallados por los intereses del capital y de los países centrales. Así, los circuitos del capital han logrado desplegarse sobre las cadenas de desarrollo regional impulsando procesos de desterritorialización y reterritorialización, en el sentido del conjunto de las acciones desplegadas por los individuos para la construcción de sus propios territorios (Haesbaert, 2011). Dado que estos procesos territoriales son relacionales, multiescalares y multidimensionales, resultan en la coexistencia de tipos territoriales diferentes, "múltiples territorios" o "múltiples territorialidades", producto de cada superposición o combinación particular. En este contexto, la élite globalizada tiene la posibilidad de hacer uso de aquella territorialidad que más le conviene en cada momento (Haesbaert, 2011). Así es como estos actores hegemónicos usufructúan los ecosistemas, territorios y bienes comunes aún no privatizados, con el objetivo de incrementar las tasas de rentabilidad del capital (Harvey, 2005).

Estos procesos territoriales han sido acompañados por la difusión, a nivel global, del discurso neoliberal que propone un avance del mercado sobre todos los aspectos de la vida social, política y económica. Contrariamente al difundido argumento propio de la doctrina neoliberal que señala una tajante oposición entre el modo de organización social del Estado y del mercado, el análisis de los procesos concretos de neoliberalización destaca la relevancia y la directa implicación del Estado en su puesta en marcha. Así, el Estado, a través de la modificación del marco normativo, de la regulación fiscal, de la provisión de infraestructuras y servicios y de la formulación de planes y proyectos o simplemente por su decisión de no intervención se constituye en un actor clave en la eliminación de las barreras para la circulación del capital y, ligado a ello, en la apropiación y producción diferencial del territorio. Por acción u omisión, el Estado coordina y actúa como árbitro frente al entramado de actores e intereses que intervienen en la configuración, el uso y el usufructo del territorio y, en concordancia, ajusta el despliegue de la nueva geoeconomía del capitalismo en lo que se ha denominado "neoliberalismo realmente existente" (Brenner \& Theodore, 2017).

En este contexto, varios de los Estados latinoamericanos, y el argentino en particular, han implementado, a principios de este siglo, un conjunto de políticas y de estrategias de desarrollo que pueden encuadrarse en el (neo)desarrollismo, entendido como una forma de oponerse a las políticas neoliberales encarnadas en la región a partir de 1970 aproximadamente. Esta estrategia, sin embargo, fue generando tensiones especialmente en lo referido al rol del Estado y a la continuidad de las actividades extractivas como motor del crecimiento económico dado que, a pesar de los intentos más o menos fructíferos de desarrollo industrial, el patrón de inserción del país siguió dependiendo de la extracción de recursos naturales y de su valor en el mercado global.

Más allá de asumir que la producción del territorio es un proceso en el cual intervienen multiplicidad de actores, con distintas cuotas de poder y capacidad de incidir en función de sus intereses, este trabajo se focaliza en la actuación del Estado en cuanto al acondicionamiento del territorio para el despliegue de las actividades extractivas, proceso que entra en tensión con las estrategias y las visiones de otros actores sociales presentes en las múltiples territorialidades. 
Consecuentemente, se propone como objetivo analizar y comparar el rol asumido por el Estado argentino en la planificación, la regulación y la producción del territorio atravesado por el despliegue de actividades extractivas en el período definido por el retorno a la planificación como política pública (2003-2015), etapa en la que el Estado modificó sustancialmente su rol y comenzó a participar activamente en la planificación del territorio y de sus actividades económicas estratégicas. Al respecto, se aclara que el recorte temporal obedece a la gestión de gobierno y no a la periodicidad de los procesos analizados; sin embargo, se hará referencia al rol del Estado en la gestión anterior para evidenciar los principales cambios, tensiones y continuidades en el manejo de las actividades.

Para su estudio específico, se definieron tres estudios de caso en provincias en las que se desarrollan actividades extractivas claves de la economía nacional: la minería en Catamarca, la soja en Chaco y los hidrocarburos no convencionales en Neuquén. El denominador común de estas actividades es que se centran en la explotación de bienes naturales mediante el accionar de actores que se reproducen a escalas mucho más amplias que las escalas de reproducción social de las comunidades locales, lo cual, en ocasiones, se traduce en conflictos sociales y ambientales visibilizados en diferentes movimientos de resistencia. La selección de estos casos obedeció, a su vez, al papel protagónico que cada una de las actividades desempeña en sus contextos provinciales - en las exportaciones y su producto bruto - y al papel estratégico de dichos espacios provinciales en la expansión del capital vinculado a cada una de las actividades.

Para llevar adelante el trabajo, se desplegó una estrategia metodológica que combinó, por un lado, la revisión de documentación oficial relativa a la planificación y la inversión pública y, por el otro, trabajo de campo con la realización de entrevistas semiestructuradas a funcionarios provinciales, municipales y otros actores relevantes del sector privado, así como organizaciones de la sociedad civil, que permitieron no solo interpretar las acciones oficiales, sino también dar cuenta de las voces de las comunidades ${ }^{4}$.

El artículo se estructura en cinco apartados. En la primera parte se conceptualiza brevemente la relación entre (neo)extractivismo y (neo)desarrollismo en el contexto de los procesos de neoliberalización, para luego avanzar en la caracterización de los casos y en el despliegue de las actividades extractivas. En el apartado siguiente se indaga por el rol del Estado en la planificación del territorio entre los años 2003 y 2015 y en las principales propuestas, proyectos y normativas relativas a las actividades extractivas analizadas. Posteriormente se analizan las intervenciones realizadas, las obras concretadas. A modo de cierre, se presentan las consideraciones vinculadas al rol asumido por el Estado en el acondicionamiento y la regulación del territorio para el desarrollo de actividades extractivas.

\section{2. (Neo)desarrollismo y (neo)extractivismo en el contexto del proceso de neoliberalización}

Este trabajo incorpora la noción de "neoliberalismo realmente existente" (Peck \& Theodore, 2019) porque resulta útil para comprender la modalidad en la que el neoliberalismo como discurso y como práctica, como "razón del mundo" (Laval \& Dardot, 2013), ha tomado forma en contextos sociohistóricos determinados. En este sentido, el neoliberalismo realmente existente es un proceso históricamente situado que se distingue del homogéneo y deslocalizado planteo ideológico del

4 El trabajo de campo en Chaco se llevó a cabo en mayo del 2015, en Catamarca, en noviembre del mismo año, y en Neuquén, en febrero del 2017. En total, se realizaron 63 entrevistas semiestructuradas que tuvieron como eje indagar sobre las problemáticas y los conflictos surgidos a partir del desembarco de las actividades y las potencialidades eventuales que se desencadenaron, contemplando la relación del entrevistado con la actividad. 
discurso neoliberal, ya que se plantea como un modo de regulación, un conjunto de reglas que se adaptan, se modifican e incluso pueden presentar contradicciones internas (Peck \& Theodore, 2019). Así, parte de su eficacia radica en su carácter procesual y sucesivo, que se impone gradualmente y que logra coexistir con otros modos de regulación preexistentes. El neoliberalismo realmente existente se encuentra, entonces, siempre inacabado, es un proyecto siempre incompleto y en permanente disputa en todos aquellos espacios en los cuales los Estados y los actores sociales impulsan sus iniciativas.

Siguiendo a Brenner et al. (2015), los procesos de neoliberalización presentan dos momentos que van alternándose de forma sucesiva y en los cuales el rol desempeñado por el Estado se vuelve central: un primer momento de destrucción de los marcos normativos preexistentes y un segundo momento de recomposición y de re-regulación orientado a garantizar la continuidad de las estrategias de acumulación del capital. Es decir que se trata de procesos fragmentados y ensamblados en los cuales se van ajustando y realizando cambios con el objeto de ampliar los márgenes de acción del mercado y del capital. La identificación de esta lógica de los proyectos de neoliberalización resulta entonces de utilidad para visualizar no solamente los matices y las contradicciones internas de estos procesos, sino también para identificar los nudos de conflicto, de resistencia y de poder que se ponen de manifiesto en cada uno de los momentos.

Se trata de procesos que requieren de la participación del Estado para su puesta en marcha a partir de la adopción de nuevas formas de regulación estatal que constantemente privilegien los intereses y las prioridades del capital global y las inversiones de empresas transnacionales (Brenner, 2003). En este sentido, se considera que:

[...] el diseño de las políticas públicas de desarrollo territorial debe ser objeto de un cuidadoso análisis crítico, ya que estas se orientan no solo a la transformación de la estructura económica de los territorios, sino fundamentalmente a asegurar la introducción de innovaciones tecnológicas y organizativas en la base productiva de cada territorio, necesarias para el funcionamiento de las empresas transnacionales (González Sousa, 2014, pp. 97-98).

Los países latinoamericanos han sido foco del avance del proceso de neoliberalización desde mediados de la década de los setenta del siglo pasado. Argentina, en particular, llevó a cabo una fuerte reforma económica y del Estado a partir de la década de los noventa que amplió con creces el margen de acción del mercado sobre múltiples esferas de la vida y condujo a una crisis política, social y económica de gran magnitud a inicios del siglo xxI. En consecuencia, la adopción de una estrategia (neo)desarrollista por parte del Gobierno entrante a comienzos de siglo ha sido la forma de enfrentar la crisis neoliberal y de canalizar la multiplicidad de demandas populares antineoliberales en el Estado (Tzeiman, 2021).

Tal como menciona Tzeiman, el (neo)desarrollismo ha sido foco de diversos desarrollos teóricos e interpretaciones que, a su vez, se funden con el análisis del propio devenir sociohistórico de los países que lo han puesto en marcha (Argentina, Brasil y Venezuela). Además de su polisemia, ha recibido numerosas críticas. De forma simplificada, el (neo)desarrollismo combinó un conjunto de políticas macroeconómicas orientadas a sostener un proceso de crecimiento económico, que promueva la innovación tecnológica y el agregado de valor y que posibilite la inserción de una economía periférica en el contexto de la mundialización del capital. A nivel político, se consolidó a partir de la presencia de un Estado fuerte, regulador, instrumento de la acción colectiva, al mismo tiempo que arena de disputas. En ese modelo, se destaca la importancia de las actividades extractivas en tanto actividades económicas que generan importantes excedentes de capital que el Estado ha intentado captar, administrar y redistribuir, no sin conflictos y resistencias 
con actores de escala nacional y global. Es en este punto que la estrategia (neo)desarrollista se presentó en oposición al avance del proceso de neoliberalización, estableciendo desde mecanismos de captación de renta hasta la reapropiación de empresas públicas y de servicios.

Por su parte, el extractivismo actual o (neo)extractivismo remite al proyecto geopolítico del capitalismo de la segunda posguerra orientado a la intensificación de nuevos medios de acumulación para captar riqueza producida por medios no capitalistas —incluido el trabajo de la naturaleza - e introducirla al sistema para abonar las tasas de rentabilidad del capital, en lo que Harvey (2005) denominó acumulación por desposesión. En concordancia, el (neo)extractivismo avanza con la consolidación de grandes empresas transnacionales especializadas en la producción y comercialización mundial de commodities y la implementación de nuevas tecnologías de explotación intensiva de bienes naturales, que involucran una mayor composición orgánica del capital y una mayor dependencia tecnológica en los territorios (Delgado Ramos, 2010; Gudynas, 2017).

Este nuevo extractivismo, más intensivo a nivel productivo, ha generado un fuerte impacto a nivel ambiental y territorial y es, en este sentido, ampliamente cuestionado por algunos de los mismos actores comprometidos con el modelo (neo)desarrollista, amplificando así las contradicciones que el proceso ha suscitado en la región. Sin embargo, el (neo)extractivismo no ha modificado radicalmente la histórica inserción internacional como exportadores de materias primas de los países latinoamericanos siendo que, a nivel interno, el (neo)desarrollismo ha implementado políticas sociales redistributivas, fomento del empleo y del consumo, ha ampliado derechos y nacionalizado empresas, en clara oposición al avance de la mercantilización y el fomento de la competencia propios del proceso de neoliberalización. En este sentido, si bien esta nueva modalidad extractiva se eslabona al (neo) desarrollismo, no es conveniente reducir el análisis de este último únicamente a su relación con la naturaleza, a fin de permitir ampliar el análisis y visualizar los conflictos y también las resistencias.

Estos procesos, con sus marcados matices y disputas, se pueden observar en Argentina a partir del análisis del rol del Estado en la regulación y el acondicionamiento del territorio para la minería metalífera a cielo abierto en Catamarca, el avance de la frontera agrícola de la soja en Chaco y la producción de hidrocarburos no convencionales en Neuquén. En efecto, el cobre, el oro, la soja y los hidrocarburos son commodities que registraron una sensible alza en sus precios durante el período 2003-2015 y esa situación del mercado global hizo que las mencionadas provincias se constituyeran en espacios estratégicos para la expansión y la reproducción del capital ${ }^{5}$. Las respectivas actividades extractivas se constituyeron en actividades económicas centrales de cada provincia: Catamarca incrementó sus exportaciones en más de 22 veces en los dos primeros años del inicio de la actividad (Instituto Nacional de Estadística y Censos de la República Argentina [INDEC], 2020); en 2016, Chaco pasó a ser la provincia con mayor superficie cultivada con oleaginosas fuera del área pampeana (Ministerio de Hacienda y Finanzas Públicas de Nación, 2016) y en Neuquén el sector energético representa el 84\% de sus exportaciones (Ministerio de Economía, 2020).

\section{Despliegue de las actividades en el territorio}

Catamarca se ubica en el noroeste argentino, sobre cordones montañosos ricos en minerales. Desde fines del siglo XIX, cuando se consolidó el modelo nacional agroexportador, la provincia presenta una débil

5 En el lapso 2003-2015, los precios del cobre, de la soja y de los hidrocarburos tuvieron incrementos sostenidos hasta el 2011, con algunas fluctuaciones producto de la crisis mundial del 2008. Posteriormente y hasta el 2015 , se mantuvieron relativamente estables, a excepción del precio del petróleo que registró una fuerte caída (Sociedad Nacional de Minería de Chile, 2021; Bolsa de Comercio de Rosario [BCR], 2015; Instituto Argentino del Petróleo y del Gas [IAPG], 2015). 
integración física y económica respecto de los ejes de desarrollo más dinámicos del país.

La minería es una actividad históricamente desarrollada en Catamarca, que se autoproclama provincia minera en su propia Constitución de 1988. A fines de siglo pasado, en el contexto de una creciente competencia global por el acaparamiento de los minerales remanentes en el planeta, una nueva tecnología de capital intensivo y explotación a cielo abierto desembarcó en Catamarca para el aprovechamiento de minerales diseminados en el yacimiento Bajo de la Alumbrera.

Como antesala a ello, el Estado encaró un profundo ajuste normativo del sector minero en pos de la atracción de las inversiones extranjeras directas que dieron origen a Minera Alumbrera Ltd. (MAA), de acuerdo con las recomendaciones del Banco Mundial. El nuevo régimen de promoción minera incluyó un tratamiento impositivo y financiero diferencial para los inversores extranjeros, habilitados para remitir las utilidades al exterior y tomar crédito interno con los mismos derechos y en las mismas condiciones que las empresas locales de capital nacional, con un marco regulatorio específico del sector minero que incluyó beneficios, exenciones, desgravaciones e incentivos exclusivos, así como ventajas sobre operaciones cambiarias y un régimen de seguridad jurídica y estabilidad fiscal que impide incrementar la carga tributaria a nivel nacional, provincial y municipal. Este hecho condicionó sobremanera cualquier intento de redistribución de la renta extractiva en los proyectos que quedaron en curso durante el período político posneoliberal.

En efecto, tras su adhesión al nuevo régimen de promoción minera establecido en la Ley de Inversiones Mineras de 1993, Catamarca fue sede del primer proyecto de megaminería en el país, desarrollado por Minera Alumbrera Ltd. (MAA), para la exportación de concentrado de cobre y oro - principalmente, aunque también se exportan otros minerales - a refinerías y fundiciones extranjeras. El proceso de construcción de la mina, los servicios, la infraestructura y el equipamiento necesario para la extracción y la comercialización del producto se inició en 1994, y en 1997 MAA comenzó a exportar.

Se trata de una modalidad de explotación a gran escala que genera fuertes afectaciones ambientales en el corto, mediano y largo plazo, inéditas en los proyectos de minería tradicional, que a su vez depende de una amplia disponibilidad de agua y de energía, en un territorio donde dichos recursos son de crítico acceso para sus pobladores, y de una amplia red de infraestructuras de transporte que viabilice el traslado de bienes de capital e insumos hacia la mina y el traslado del mineral en bruto hacia el puerto de exportación.

El yacimiento se encuentra en Catamarca, pero el proceso productivo involucra varias provincias. Desde Buenos Aires y pasando por Córdoba y La Rioja ingresan maquinarias, explosivos, gasoil y otros insumos, la energía es generada en Tucumán y transportada por una línea de alta tensión privada de la empresa, mientras que el agua se extrae en Catamarca. Para la exportación, el producto - barro mineralse traslada desde Catamarca por un mineraloducto hacia Tucumán, donde se le quita su humedad en una planta de filtros, para luego ser transportado en tren en forma de polvo hacia el puerto que MAA administra sobre el río Paraná, al norte de Puerto General San Martín en la provincia de Santa Fe. Hasta allí, acceden buques de ultramar que conectan directamente con los mercados internacionales (Figura 1). 


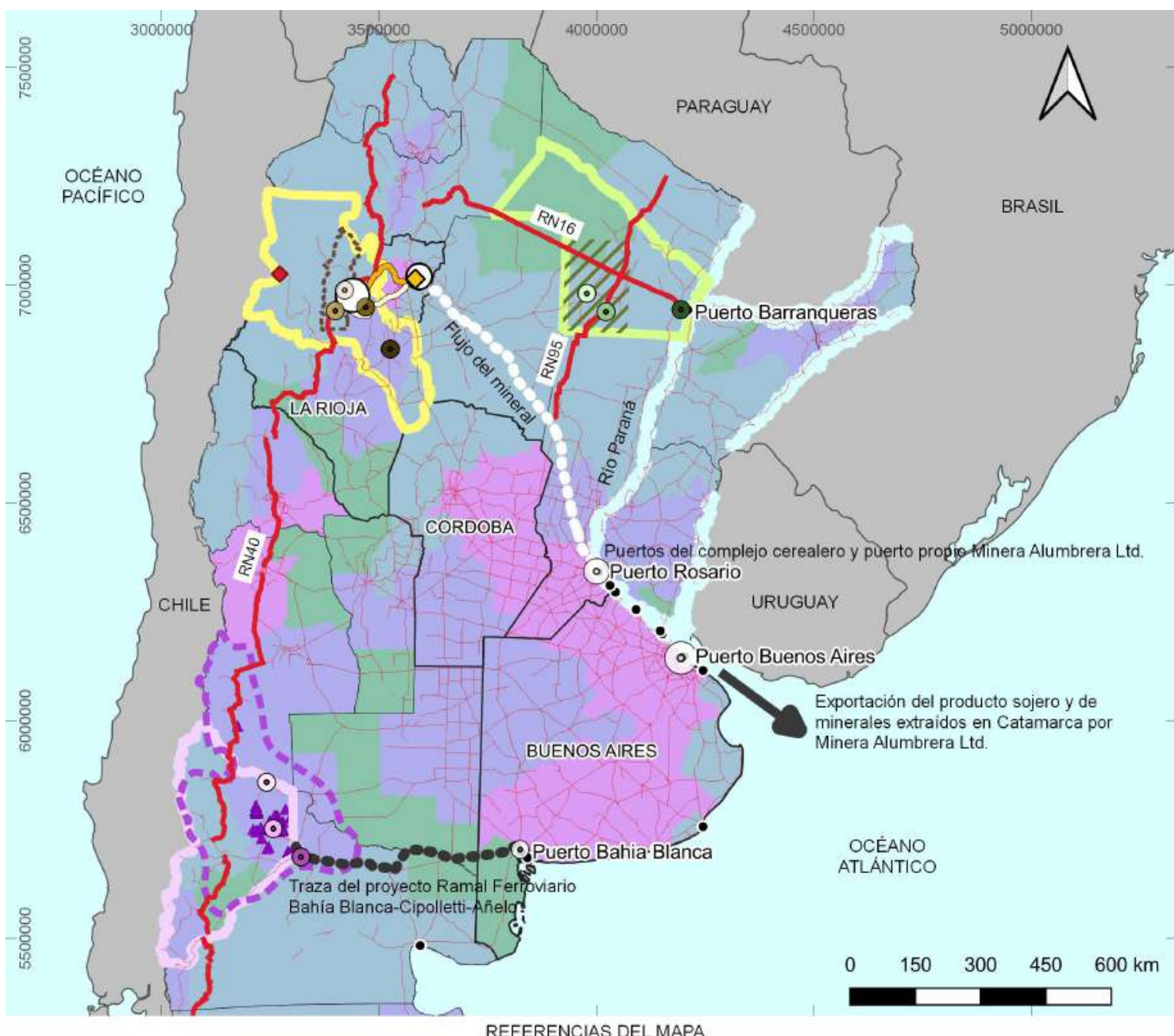

\begin{tabular}{|c|c|}
\hline \multicolumn{2}{|c|}{ Provincia de Catamarca } \\
\hline & Provincia de Chaco \\
\hline & Provincia de Neuquén \\
\hline & Limites provinciales de provincias mencionadas en el texto \\
\hline & Otros limites provinciales \\
\hline & Departamento de Belén (Prov. Catamarca) \\
\hline & Área de expansión sojera en Chaco \\
\hline$=-2$ & Cuenca productiva Vaca Muerta \\
\hline 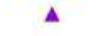 & Pozos hidrocarburos no convencional en explotación (2018) \\
\hline & Línea 220Kv El Bracho-Minera Alumbrera Ltd. \\
\hline & Mineraloducto Minera Alumbrera Ltd. Catamarca-Tucumán \\
\hline & Minera Alumbrera Ltd. (localización de la mina) \\
\hline 0 & Central Térmica El Bracho (Tucumán) \\
\hline O & Planta de Filtros Minera Alumbrera Ltd. (Tucumán) \\
\hline (อ) & Hualfin \\
\hline ๑ & Belén \\
\hline • & Andalgalá \\
\hline - & San Fernando del Valle de Catamarca \\
\hline • & Charata \\
\hline • & Villa Ángela \\
\hline
\end{tabular}

\begin{tabular}{|c|c|}
\hline \multicolumn{2}{|l|}{ Resistencia } \\
\hline \multicolumn{2}{|c|}{ Rincón de los Sauces } \\
\hline \multicolumn{2}{|l|}{ Añelo } \\
\hline \multicolumn{2}{|l|}{ Ciudad de Neuquén } \\
\hline \multicolumn{2}{|l|}{ Rosario } \\
\hline \multicolumn{2}{|c|}{ Ciudad de Buenos Aires } \\
\hline \multicolumn{2}{|l|}{ Bahia Blanca } \\
\hline \multicolumn{2}{|c|}{ Paso San Francisco (Argentina-Chile) } \\
\hline \multicolumn{2}{|c|}{ Principales áreas portuarias del pais } \\
\hline \multicolumn{2}{|c|}{ FFCC Nuevo Central Argentino. Corredor Tucumán-Rosario } \\
\hline \multicolumn{2}{|c|}{ FFCC Roca Concesion Ferrosur Roca } \\
\hline \multicolumn{2}{|c|}{ Red vial pavimentada (2018) } \\
\hline \multicolumn{2}{|c|}{ Rutas nacionales mencionadas en el texto } \\
\hline \multicolumn{2}{|c|}{ Rios navegables con regimen permanente } \\
\hline \multirow{2}{*}{\multicolumn{2}{|c|}{$\begin{array}{l}\text { Argentina: Perfil del complejo económico regional } \\
\text { Industrial }\end{array}$}} \\
\hline & \\
\hline \multicolumn{2}{|l|}{ Industrial/Primario } \\
\hline Primario/Industrial & $\begin{array}{l}\text { SISTEMA DE REFERENCIA } \\
\text { Provección: Conforme de Gauss }\end{array}$ \\
\hline Primario & Datum: RAMSAC \\
\hline
\end{tabular}

FIGURA 1. Localidades de análisis: circuitos de la economía extractiva y proyectos en las provincias de Catamarca, Chaco y Neuquén

FUENTE: elaboración propia con base en interpretación visual de imágenes satelitales provistas por Google y consulta de información geográfica pública del Instituto Geográfico Nacional (IGN), el Ministerio de Energía y Minería y el Observatorio de Empleo y Dinámica Empresarial del (ex) Ministerio de Trabajo, Empleo y Seguridad Social. Realizado mediante la utilización del sistema de información geográfica de software libre QGIS 3.10. 
MAA es reconocida como un "Estado" dentro de la provincia: tiene policías propios, limita el acceso de controles municipales, no permite sobrevolar sobre su territorio y prohíbe el paso hacia la mina. MAA se relaciona con las comunidades próximas mediante la figura de la responsabilidad social empresaria, buscando legitimar su presencia en el territorio con el financiamiento o entrega de proyectos, obras e insumos muy visibles para las comunidades locales. Sin embargo, este control por parte de la empresa es denunciado por actores locales de Andalgalá que señalaron: "El territorio de la minera no es argentino, es de la multinacional, tienen trancas por todos lados, servicios de matones por todos lados" (Entrevista con un ingeniero agrónomo del área de investigación del Instituto $\mathrm{Na}$ cional de Tecnología Agropecuaria [INTA], delegación Andalgalá). En el mismo sentido, una productora agrícola local acusó limitaciones a la circulación por los predios que atraviesa el mineraloducto: "por Villa Vil está cerrado, en un punto hay un portón y están ellos cuidando. [...] la misma gente que tiene campos, animales, no tiene paso, tiene que pedirles permiso" (Entrevista con productora agrícola de Andalgalá).

Por su parte, la provincia de Chaco, hacia donde avanzó la frontera agraria de la mano de la producción sojera industrial transgénica, se ubica en el nordeste argentino en un área de llanura que presenta, en comparación con las áreas pampeanas del centro del país, condiciones menos ventajosas para la producción agrícola tradicional. Hasta fines del siglo XIX, el territorio chaqueño mantuvo cierta autonomía. Desde ese entonces, de la mano de la inmigración como política de Estado para ocupar el territorio, las actividades extractivas - maderas, caucho y algodón- constituyeron su perfil económico (Figura 1).

El avance de la frontera de la soja en la provincia es consecuencia de una serie de cambios normativos propios de la década de los noventa del siglo pasado orientados a la desregularización de la política agraria, que redujo el margen de control del Estado ampliando la esfera de acción del mercado. Entre los puntos más relevantes se encuentra el Decreto 2284 (1991) que desregula el comercio exterior y disuelve la Junta Nacional de Granos, ente encargado de la regulación del mercado y la actividad agraria. A su vez, un conjunto de leyes (Ley de semillas y Ley de patentes), desde 1996, permitieron la introducción de un nuevo "paquete tecnológico" que viabilizó la expansión del cultivo de soja hacia tierras menos favorables para la producción de oleaginosas, de la mano de la semilla transgénica y a costa de la ganadería, de la producción de cultivos tradicionales y de miles de hectáreas de bosques nativos.

La provincia autorizó los desmontes de bosques y actividades de silvicultura, que encubrieron estrategias para el avance de la soja ${ }^{6}$. La expansión de este cultivo se produjo en el contexto de la flexibilización de las leyes de arrendamiento y la posibilidad de hacer contratos eventuales por una cosecha, lo cual le permitió a los grandes propietarios obtener el concurso de contratistas para sembrar soja y o tros cereales y oleaginosas. Desde entonces, casi toda la producción sojera es transgénica y se destina a exportación.

A diferencia de las actividades agrícolas tradicionales de Chaco, la producción sojera se estructura en unidades de explotación empresarial que concentran mayor capital, mayor superficie y que ocupan trabajadores especializados de acuerdo al modelo de la agricultura industrial. En concordancia, para facilitar la logística de provisión de maquinaria, de fertilizantes y de insumos hacia los campos sojeros, así como para el transporte del producto hacia mercados globales, se acondicionó la infraestructura de transporte que soporta esos flujos. El despacho de la soja y de sus subproductos se realiza mayormente desde puertos sobre el río Paraná.

En el desarrollo de la actividad sojera en Chaco, a diferencia de la minería concentrada, hay una amplia diversidad de actores involucrados. Si bien existen productores y transportistas de distintos tamaños,

6 Entrevista realizada en el Centro de Estudios e Investigación Social Nelson Mandela. 
los tres grandes sectores en los que se concentra el negocio de la soja son: 1) pools de siembra constituidos por fondos de inversión, 2) empresas transnacionales proveedoras de agroquímicos - Monsanto, Novartis, Dupont y Bayer, entre otras - y 3) cinco grandes compañías exportadoras que administran el 90\% de la comercialización - Cargill, Bunge, Dreyfus, Nidera y Aceitera General Deheza-, que exportan desde sus propios complejos portuarios construidos tras la Ley de Puertos sancionada en el año 1992 (Morina \& Cacace, 2017). En una entrevista realizada en el Centro de Estudios e Investigación Social Nelson Mandela de la provincia de Chaco, se acusa que las tecnologías de la soja y la economía de escala han traducido cambios en la tenencia de la tierra y en el uso del suelo. Producto de ello, el propietario minifundista que antes vivía con el rendimiento de 100 ha ya no puede retener la tierra por los altos costos y la arrienda a productores sojeros más grandes.

La provincia del Neuquén se ubica en el norte de la Patagonia y se extiende sobre la formación geológica de Vaca Muerta, una importante reserva de gas y petróleo no convencional. La actividad hidrocarburífera convencional se desarrolla en Neuquén desde 1918 y desde los años veinte del siglo pasado los geólogos conocían la existencia de los recursos de la cuenca neuquina. Con los sucesivos avances tecnológicos, su magnitud y ubicación se fueron determinando con mayor exactitud, pero no fue hasta el 2010 que una parte de ellos pasaron a ser técnicamente recuperables. La entonces Repsol-yPF inició la divulgación acerca de las importantes dimensiones del yacimiento de la cuenca neuquina, luego del éxito obtenido en los primeros pozos no convencionales en Vaca Muerta. La combinación entre una modificación técnica para la extracción hidrocarburífera en reservorios no convencionales y el alza del precio hicieron posible la extracción de recursos que hasta entonces no eran considerados viables.

Entonces, a diferencia de la megaminería en Catamarca y la soja transgénica en Chaco, la actividad hidrocarburífera no convencional se inicia en el contexto (neo)desarrollista. Hasta ese momento, el sector hidrocarburífero se encontraba desregulado como consecuencia de la implantación del proyecto neoliberal en 1990. El Estado argentino se había retirado del sector y facilitado una alta concentración empresarial y amplios márgenes de ganancia al sector privado, a la vez que había procedido al vaciamiento y la fragmentación de la empresa hidrocarburífera nacional - que incluyó la tercerización de diferentes etapas productivas y la precarización laboral de sus empleados - para favorecer su privatización y ofrecer mayores beneficios a las adjudicatarias.

Para extraer el petróleo y el gas de Vaca Muerta se requieren procesos tecnológicos de estimulación hidráulica. Esta modalidad exige un mayor despliegue logístico que vuelve más costosa su operación que la explotación convencional, por ello es necesario que el precio internacional de los hidrocarburos se mantenga alto para que sea rentable. A su vez, requiere de personal calificado para el trabajo en los pozos y la disponibilidad de grandes volúmenes de agua, arena y productos químicos. Asimismo, para el traslado hacia las refinerías y los polos petroquímicos, demanda una red de ductos. Si bien esta actividad se despliega sobre inversiones que la preceden, exige mejoras en rutas y en vías férreas, así como ampliación del equipamiento y de la infraestructura (Figura 1).

YPF, parcialmente renacionalizada con el 51\% del paquete accionario bajo control estatal y el $49 \%$ restante en manos privadas, opera bajo la forma jurídica de una sociedad anónima y es una de las empresas que lidera las inversiones. Desde el 2012, es una de las concesionarias más grandes de las áreas de exploración y explotación, dentro de un entramado de empresas transnacionales que realizan actividades de extracción. Asimismo, un conjunto de importantes empresas multinacionales domina la provisión de servicios especializados, mientras que las pequeñas y medianas empresas provinciales participan de la provisión de bienes y servicios de menor complejidad y 
especialización. En este entramado de actores tienen peso relevante los sindicatos de la industria petrolífera, de la construcción y camioneros.

Por otro lado, dado que las zonas de explotación coinciden parcialmente con tierras de las comunidades mapuches, el reconocimiento de algunas de las comunidades y la insuficiencia de instrumentos legales de propiedad de la tierra son nudos de conflicto en la actividad.

\section{El territorio pensado: el Estado en la planificación territorial}

A partir de los años setenta, y más aún en los noventa, el Estado delegó el manejo de los recursos naturales en las provincias y se desligó de diversas funciones en favor de distintos actores privados (desde empresas de servicios públicos hasta la gestión de la documentación de identidad). Abandonó la ejecución y el mantenimiento de obras y se reservó tareas de control, en general débilmente ejecutadas. En ese marco de hegemonía neoliberal se reglamentaron las actividades mineras, se habilitó la innovación en materia de semillas, se desregularizó la actividad hidrocarburífera y se privatizó YPF. En ese contexto, se instaló MAA en Catamarca (1994) y avanzó la explotación sojera en Chaco de la mano de las semillas transgénicas (1996).

A comienzos del siglo XXI se produjo un giro en el horizonte trazado por las políticas neoliberales precedentes surgidas del Consenso de Washington. El Gobierno iniciado en 2003 llegó con un discurso contrario al modelo hegemónico neoliberal, apuntando a una mayor intervención en el desarrollo económico y social del país. El Estado (re)cobró protagonismo en la realización de inversiones, la regulación de actividades y el diseño de políticas territoriales, con una fuerte presencia en la planificación, la gestión y la producción del territorio que se sostuvo hasta fines del 2015.
Si bien un conjunto de políticas da cuenta de este giro $^{7}$, buena parte de las regulaciones y las concesiones previas que brindaron la seguridad jurídica a las empresas del sector extractivo siguieron vigentes. De todas formas, en el marco de una fuerte tensión entre el Gobierno y los actores hegemónicos de la economía extractiva, se aplicaron ciertos mecanismos político-institucionales dirigidos a captar, administrar y redistribuir la renta extraordinaria del sector, producto del vertiginoso aumento en el precio de los commodities de comienzos de siglo.

Uno de los cambios ponderables en el rol del Estado fue, indudablemente, la planificación de inversiones y actividades económicas en el territorio nacional, con modificaciones institucionales que incluyeron la jerarquización de áreas ligadas a la planificación, la realización de obras públicas y la formulación de planes estratégicos. Así, entre 2003 y 2015 se elaboraron numerosos planes y proyectos que alcanzaron distintos grados de avance y que evidencian la existencia de un Estado que asumió un rol activo en la definición y la articulación de políticas públicas ligadas a procesos de desarrollo regional, entre ellos, el Plan Estratégico Territorial, el Plan Estratégico Agroalimentario y Agroindustrial Participativo y Federal, el Plan Estratégico Industrial, el Plan Energético Nacional (Ministerio de Planificación Federal, Inversión Pública y Servicios [MINPLAN], 2004a), el Plan Minero Nacional (MinPlan, 2004b) y el Plan Nacional de Telecomunicaciones (Schweitzer et al., 2017).

El más significativo de esos fue el Plan Estratégico Territorial (PET), iniciado en el 2004 desde el Ministerio de Planificación Federal, Inversión Pública y

7 El Estado comienza a intervenir en temas tales como la renegociación de la deuda externa realizada en 2005, interviene en el congelamiento de las tarifas de servicios públicos, realiza acuerdos para la fijación de precios de bienes de consumo, recupera el sistema previsional privatizado en la década de los noventa, interviene en acuerdos salariales con la participación de los sectores sindicales y recupera la gestión de las empresas de servicios públicos privatizadas en el período anterior, como Aguas Argentinas, el Correo Argentino e YPF. 
Servicios $^{8}$, que cuestiona que sea el mercado quien defina la inversión en infraestructuras por la inequidad territorial que ello provoca. Desde ese marco, se alentaron inversiones para arribar a un desarrollo territorial más equilibrado y disminuir la vulnerabilidad económica y social en amplias áreas del país que incluyen proyectos ligados a las actividades extractivas que se presentan ${ }^{9}$.

En cuanto a las normativas, en materia minera el Estado fijó las condiciones generales para el desarrollo de la actividad en la década de 1990, que continuaron sin mayores alteraciones entre 2003 y 2015. Sin embargo, es posible identificar ciertas diferencias como la implementación de derechos de exportación a partir del 2007 y las retenciones a la minería. En diciembre de 2015, con el cambio de Gobierno, se desactivó este mecanismo. Por otro lado, las provincias son las que cobran y gestionan las regalías mineras, cuya alícuota máxima no puede ser modificada para el caso de MAA dada la seguridad jurídica otorgada en la década de 1990. En materia de control ambiental, siguió a cargo de las provincias sin la mediación de estrategias de fortalecimiento de sus capacidades en la materia.

En el caso del Chaco, la regulación en torno a la actividad sojera continuó siendo escasa en el período y estuvo limitada a la imposición (siembre conflictiva) de retenciones a la exportación. Se entiende que el Gobierno provincial habilita, por omisión, la particular configuración territorial que promueven los actores vinculados al negocio sojero. Si bien no hay regulaciones específicas para la actividad sojera, hay leyes provinciales que actúan sobre el accionar de los actores vinculados e interpelados por la actividad, como la Ley Provincial n 5285 de bosques, que es cuestionada particularmente por dejar en manos del

8 El PET tuvo sucesivos avances $(2008,2011,2015)$ en los cuales se trabajó juntamente con los equipos provinciales. Una nueva versión apareció luego del cambio de Gobierno (2018).

9

Entre ellos se destaca la construcción de un ramal ferroviario - entre Bahía Blanca, Cipolletti y Añelo- para el traslado de cargas hacia Vaca Muerta y proyectos que mejoran la navegabilidad del río Paraná para la exportación de soja y minerales con costos reducidos.
Gobierno provincial la autorización de los desmontes, que representan una forma encubierta de flexibilizar los controles y permitir el avance de la frontera sojera.

Del mismo modo es cuestionada la adjudicación de tierras por parte del Instituto de Colonización ${ }^{10}$, porque habría facilitado el avance de los pools de siembra en detrimento de los pequeños y medianos productores, los campesinos y los pueblos originarios. Las organizaciones ambientalistas entrevistadas mencionan que si bien según la legislación vigente solo se pueden ofrecer tierras a actores locales (productores agropecuarios, maestros y personas relacionadas con el sector agrícola con más de cinco años de residencia en el lugar), la ausencia de control permite el acceso de empresarios de las provincias vecinas de Córdoba y de Santa Fe, que las adquieren mediante testaferros locales ${ }^{11}$.

En relación con la normativa, en el caso de Neuquén, una de las primeras medidas implementadas luego de la crisis del 2001 fue la reinstalación de los derechos de exportación, desvinculando la cotización interna del crudo de los precios internacionales ${ }^{12}$. En 2012, tras la publicación de la entonces Repsol-yPF acerca de las importantes reservas de Vaca Muerta, se sancionó la Ley de Soberanía Hidrocarburífera (Ley 26.741) (Boletín Oficial de la República Argentina, 2012). En dicha ley, el Estado nacional autorizó, por un lado, la expropiación del 51\% del capital accionario de YPF S.A., hasta entonces en manos de Repsol, y, por otro lado, declaró de interés público nacional el autoabastecimiento de hidrocarburos y creó el Plan Nacional de Inversiones Hidrocarburíferas para la exploración, explotación, refinación, transporte y comercialización de hidrocarburos. De ese modo, se posibilitó la

10 Organismo provincial encargado de gestionar las tierras fiscales.

11 Esta situación fue remarcada en la entrevista realizada en el Centro Nelson Mandela, una organización que llevó a cabo un conjunto de denuncias por irregularidades en la administración del territorio provincial.

12 En el año 2002, dado el colapso económico ocurrido en el país, el Gobierno implementó los derechos de exportación para los hidrocarburos para generar recursos destinados a asistir a los sectores más vulnerables. En la gestión comenzada en 2003 se sostuvo la medida hasta alcanzar un sistema de retenciones móviles, que se ajustaban en función del precio internacional del crudo. 
toma de control del Estado nacional sobre uno de los sectores claves para el desarrollo y sobre un bien estratégico, como los recursos energéticos en general y los hidrocarburos en particular.

En ese sentido, en 2012 el Estado nacional volvió a posicionarse como un actor clave en las negociaciones entre los Estados provinciales y las grandes empresas operadoras de los yacimientos. En cuanto al Estado provincial, sus competencias oscilan entre la gestión de los recursos naturales y las implicancias ambientales, sociales y económicas generadas por el desarrollo de la actividad. Asimismo, es el encargado de cobrar y gestionar las regalías por la explotación, que comparte con los municipios que participan de la actividad, y tiene la potestad para negociar los contratos de asignación de áreas de exploración y explotación de hidrocarburos. En este caso, es relevante el accionar que ha tenido el Gobierno provincial a favor de impulsar a las pequeñas y medianas empresas a formar parte de la cadena de valor ${ }^{13}$.

Por su parte, a partir de las entrevistas realizadas, se ha observado que el Gobierno municipal de Añelo intentó reposicionarse en el entramado decisional para negociar mejoras de infraestructura y equipamiento para la localidad, aunque aún no ha logrado incidir en decisiones relativas a la dinámica y el control de la actividad.

En cuanto a los proyectos diseñados entre 2003 y 2015 para las tres provincias analizadas, se observa una correspondencia entre la cantidad de proyectos priorizados por el $\operatorname{PET}^{14}$ y los precios que los commodities acusaron en el mercado. Así, Neuquén lideró notablemente la cartera de proyectos luego del alza del precio del petróleo y en Catamarca la mayor cantidad de proyectos se verificó en paralelo a los años en los

13 Se destaca la Ley 2.755, Compre Neuquino, reglamentada en 2013, que promueve la compra de bienes y servicios provenientes de empresas, uniones de empresas y profesionales independientes radicados en la provincia (Secretaría de Biblioteca y Jurisprudencia del Poder Judicial, 2010).

14 Si bien se entiende que la cuantía de proyectos no representa las magnitudes físicas ni económicas de los mismos, se considera que ello habilita realizar un análisis comparativo de los distintos ámbitos geográficos y temáticos en los que se indaga. que el precio internacional del cobre fue mayor, al igual que sucedió en Chaco respecto al precio de la soja.

En Catamarca primaron los proyectos viales y energéticos. Entre los que atienden necesidades de MAA, al margen de la pavimentación de la RN40 en los tramos de mayor circulación de los flujos asociados a la actividad minera y la RP46 que conecta las dos cabeceras departamentales más próximas al emprendimiento minero, se destaca el proyecto para mejorar la circulación por el Paso San Francisco en la frontera con Chile, desde donde ingresan algunos insumos hacia la mina y se exporta en camión el concentrado mineral de molibdeno. Otro proyecto para usufructo de MAA fue la ampliación de la Estación Transformadora El Bracho, en Tucumán, desde donde se abastece de energía al yacimiento minero. Por otra parte, en el PET se planteó la jerarquización de las localidades de Andalgalá y de Belén, las cabeceras departamentales más próximas a Bajo de la Alumbrera.

En Chaco, el sector vial lideró la cartera de proyectos, seguido por las iniciativas en temas hídricos. Entre ellos se propuso la pavimentación de la RN95 y la RP13, rutas que sirven a los flujos de la producción agrícola en la provincia, la recuperación del ferrocarril Belgrano Cargas en tramos puntuales del llamado ramal cerealero, así como acciones concretas para el Puerto Barranqueras, que opera con barcazas por su limitada profundidad. Por su parte, el PET III planteó el fortalecimiento de Charata y Villa Ángela, dos localidades nodales en el área de expansión de la frontera del cultivo de soja en la provincia.

En Neuquén, la mayor parte de los proyectos también fueron para el área vial. Se propusieron mejoras en las rutas vinculadas a la localidad de Añelo, la más próxima a las nuevas áreas de explotación, y en la ruta provincial que conecta Rincón de los Sauces, la segunda localidad hidrocarburífera de la provincia, con la RN40. Los centros urbanos de Añelo y Rincón de los Sauces fueron planteados como nodos multimodales claves en el territorio neuquino. En ambas localidades se propusieron obras de saneamiento y de electrificación, que atienden a la gran cantidad de población que llegó a esas localidades en busca de empleo tras el impulso de 
Vaca Muerta. Se han propuesto también mejoras en el aeropuerto de Neuquén y en la red de fibra óptica.

\section{El rol del Estado: del territorio pensado al territorio producido}

Si en el apartado anterior se incluyeron las regulaciones y las normativas que condicionan y orientan las intervenciones y las expectativas que se generan en la sociedad, este punto se focaliza en la identificación de los proyectos concretados y financiados por el Estado en sus diferentes niveles de gobierno, cuyo análisis permite dar cuenta del modo en que el Estado argentino acondiciona el territorio en clave del despliegue de las actividades extractivas-intensivas bajo estudio ${ }^{15}$.

En relación con las obras que atienden demandas del proceso productivo de la minería a cielo abierto en Catamarca, se han concretado los trabajos en el Paso San Francisco y otros sobre la RN40, enunciados anteriormente, y un desvío para evitar que el transporte de cargas atraviese la localidad de Hualfín. Al igual que en los proyectos, en las obras concretadas despunta el sector vial: entre 2003 y 2015 este sector representó el 85,7\% de la inversión pública registrada en el Banco de Proyectos de Inversión Pública (BAPIN) (Dirección Nacional de Inversión Pública, Jefatura de Gabinete de Ministros, 2021). Dentro de estas obras, el mayor porcentaje se destinó a la repavimentación de la RN40 con el objetivo de optimizar las condiciones de circulación y de seguridad del transporte pesado durante todo el año, favoreciendo de esa forma los flujos megamineros.

En la Figura 2 pueden observarse distintos elementos citados en el texto, los lineamientos generales del PET y los proyectos y las obras estatales en materia de

15 Para la identificación de las obras concretadas, se ha trabajado con la base de datos del Banco de Proyectos de Inversión Pública (BAPIN) (Dirección Nacional de Inversión Pública, Jefatura de Gabinete de Ministros, 2021), donde constan todos los proyectos de inversión pública iniciados por cualquier dependencia estatal -local, provincial o nacional_ asociada al Sistema Nacional de Inversiones Públicas (SNIP). No forman parte de esta base de datos las obras de infraestructura realizadas por las empresas. transporte, energía y recursos hídricos que acaecieron entre 2003 y 2015 en la provincia de Catamarca y el espacio operativo de MAA en el noroeste argentino (NOA).

En cuanto a la relación entre los montos de inversión pública concretados en Catamarca y las variaciones en el precio del cobre, es posible inferir que las inversiones efectuadas habrían estado vinculadas a las expectativas en el incremento de la producción minera. En ese sentido, la mayor alza interanual se verificó en los años 2005 y 2006 y el año 2007 fue el que registró la mayor inversión pública, con la mencionada repavimentación de la RN40 realizada por el Estado nacional a través de la Dirección Nacional de Vialidad.

En la provincia de Chaco también predominaron las inversiones en el sector vial, pero, a diferencia de Catamarca, los montos han sido distribuidos con mayor dispersión entre proyectos viales, fluviales y ferroviarios. La inversión para el sector vial representó el $35 \%$ del total, y de ese porcentaje más de la mitad fue destinado a la RN16. Se trata de una ruta que articula el territorio de expansión del cultivo de soja en las provincias de Chaco, Santiago del Estero y Salta con otras que llegan a los puertos de la Hidrovía (RN34, RN95, RN89 y RN11) en donde se encuentran los complejos portuarios que procesan y almacenan la soja para su exportación. Por su parte, el sector ferroviario recibió el 25\% de las inversiones en el corredor cerealero que conecta los sitios de producción con los puertos de Rosario. Respecto al sector fluvial, se registró el dragado integral del Riacho Barranqueras con la intención de que el Puerto de Barranqueras recobre su dinamismo. Se sumaron obras vinculadas a servicios agrícolas, de infraestructura urbana y obras hídricas ${ }^{16}$. En la Figura 3 pueden observarse distintos elementos referenciados en el texto, los lineamientos generales del PET y los proyectos y las obras estatales en materia de transporte, energía y recursos hídricos que acaecieron entre 2003 y 2015 en la provincia de Chaco.

16 Se trata de obras de potabilización, de captación de agua, de tratamiento de líquidos cloacales y de acueductos, dispersos en gran parte de la provincia. 


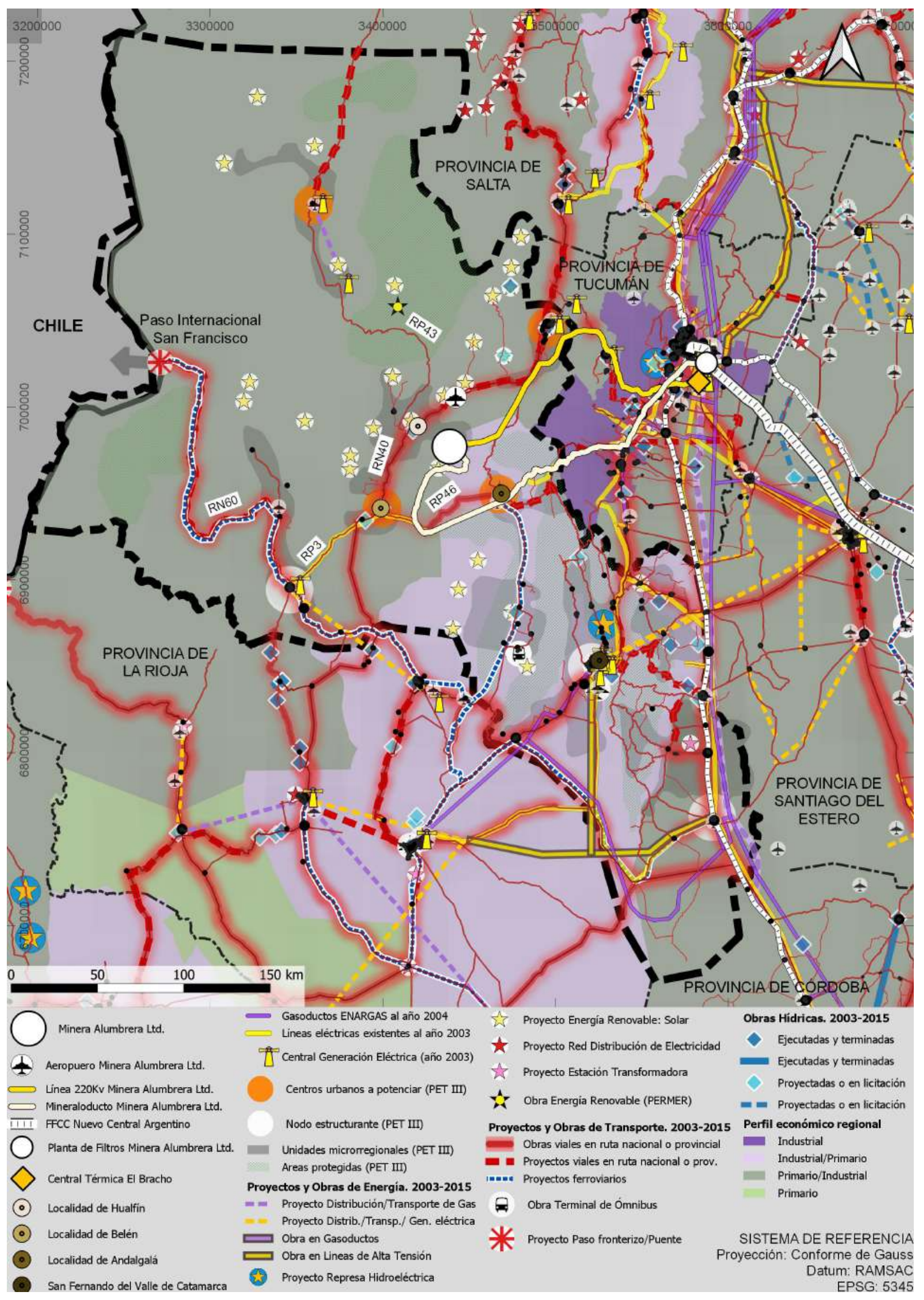

FIGURA 2. Obras y proyectos en la provincia de Catamarca, 2003-2015

FUENTE: elaboración propia con base en datos georreferenciados publicados en los Planes Energéticos

Nacionales PET I, PET II y PET III, IGN (SIG250), Ministerio de Energía y Minería, Ente Nacional Regulador del Gas (ENARGAS), Ministerio de Interior y Transporte e interpretación de imágenes satelitales de Google. 


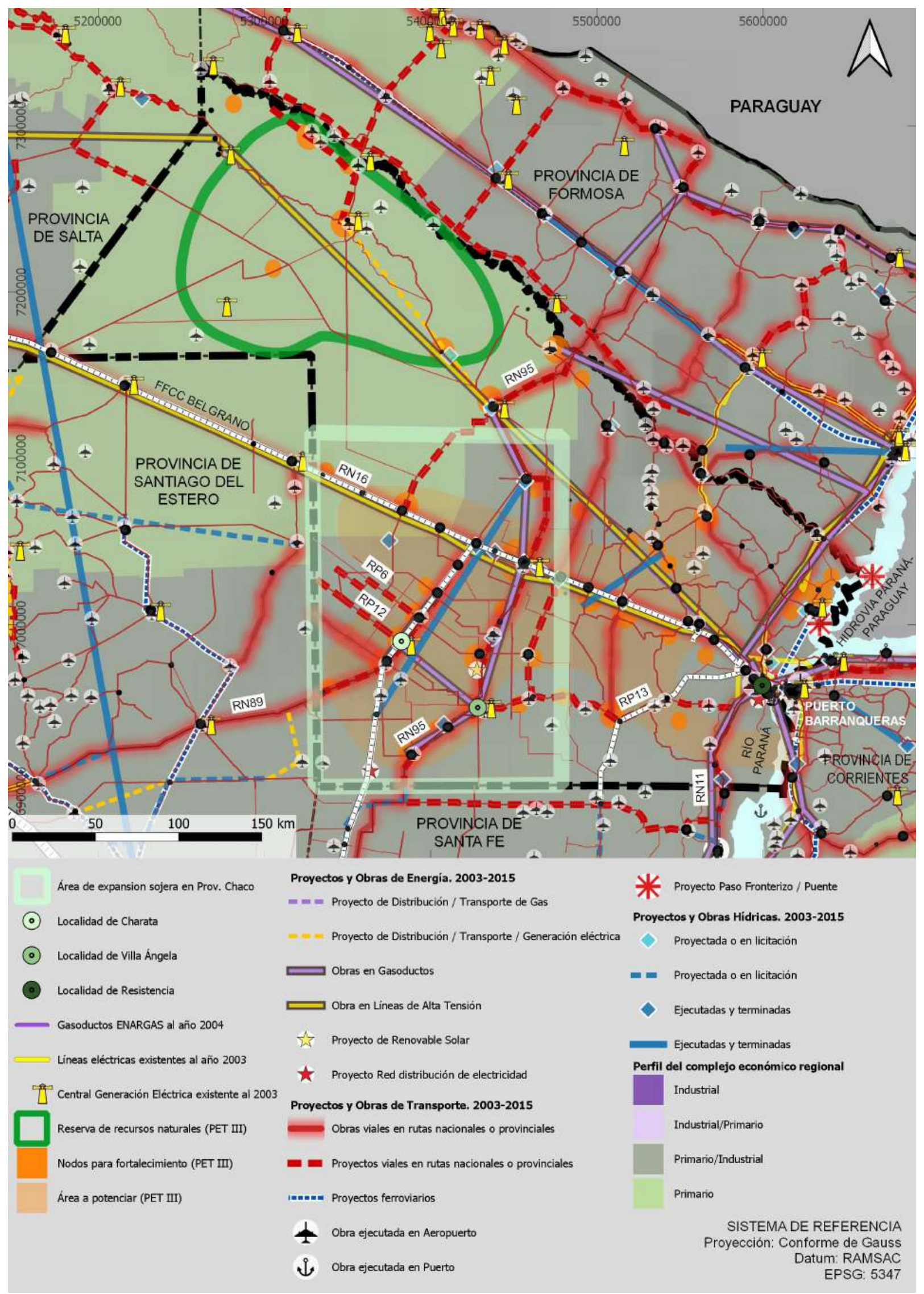

FIGURA 3. Obras y proyectos en la provincia de Chaco, 2003-2015

FUENTE: elaboración propia con base en datos georreferenciados publicados en PET I, PET II y PET III, IGN (SIC250), Ministerio de Energía y Minería, ENARGAS, Ministerio de Interior y Transporte e interpretación de imágenes satelitales de Google. 


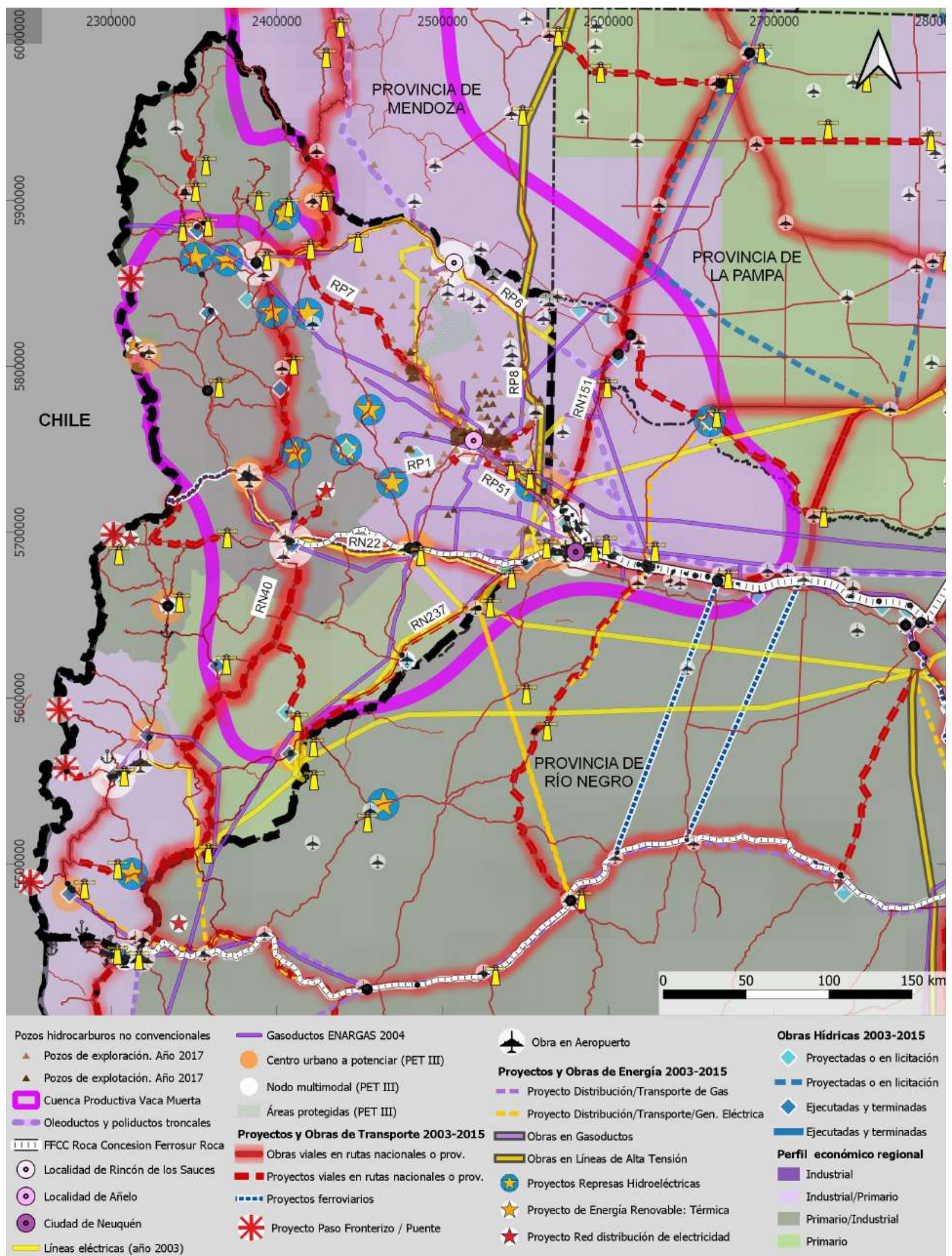

SISTEMA DE REFERENCIA Proyección: Conforme de Gauss Datum: RAMSAC
EPSG: 5344

FIGURA 4. Obras y proyectos en la provincia del Neuquén, 2003-2015

FUENTE: elaboración propia con base en datos georreferenciados publicados en PET I, PET II y PET III, Plan Energético Nacional (MINPLAN, 2004a), IGN (SIG250), Ministerio de Energía y Minería, ENARGAS, Ministerio de Interior y Transporte e interpretación de imágenes satelitales de Google. 
$\mathrm{Al}$ analizar la evolución del precio de la soja con respecto a la ejecución de la inversión pública en obras realizadas, se puede observar que la variación de los montos de inversión en infraestructuras ha ido acompañada, con un desfasaje de uno o dos años, por la tendencia de los cambios globales del precio de la soja.

En Neuquén se han concretado obras viales sobre la RN40 y en las rutas de acceso a la capital provincial, a las localidades de Añelo y de Rincón de los Sauces, en pos de facilitar los flujos vinculados a la producción en Vaca Muerta. La provincia del Neuquén, más allá de su definición como provincia energética, tiene una actividad turística destacada a nivel nacional. Hacia ese sector se direccionaron las inversiones públicas entre 2003 y 2015. En ese período no se registraron proyectos para las áreas de Añelo y de Rincón de los Sauces, por lo que se entiende que las inversiones concretadas en estos sitios se han realizado sin haber estado integradas al BAPIN. Al respecto, es relevante considerar que Neuquén contaba, antes del desarrollo de la actividad hidrocarburífera no convencional, con una base de infraestructuras más desarrollada que en los otros dos casos de estudio.

En la Figura 4 pueden observarse distintos elementos referenciados en el texto, los lineamientos generales del PET, los pozos de exploración y explotación de hidrocarburos no convencionales y los proyectos y las obras estatales en materia de transporte, energía y recursos hídricos que acaecieron entre 2003 y 2015 en la provincia de Neuquén y en la cuenca productiva de Vaca Muerta.

A diferencia de lo visto para las provincias de Catamarca y de Chaco, en donde se registra una correlación entre el aumento de la inversión pública y del precio del commodity de referencia, la mayor parte de la inversión pública en la provincia del Neuquén se ejecutó independientemente del precio del petróleo y se ligó más a la inercia de los requerimientos de actividades que vienen desarrollándose históricamente en la región.

\section{Consideraciones finales}

Este trabajo se propuso analizar el rol asumido por el Estado argentino en la planificación, la regulación y la producción en territorios atravesados por el despliegue de actividades extractivas claves de la economía nacional, en el período caracterizado como (neo)desarrollismo. En el desarrollo se pusieron de manifiesto las múltiples tensiones experimentadas por el accionar del Estado, que osciló entre acciones de freno al avance del proceso de neoliberalización y las presiones ejercidas por las elites globalizadas y entre la consolidación de un Estado catalizador de las demandas sociales y las dificultades económicas y financieras propias de un Estado dependiente.

En este sentido, pese a que a partir del 2003 el Estado ejerció un rol más activo interviniendo en muchos casos sobre la relación con el mercado, para los estudios de caso de minería y soja, el accionar del Estado nacional no implicó un verdadero quiebre con el modo de intervención puesto en marcha a partir de 1990. En efecto, se continuó sosteniendo un marco regulatorio a favor de grandes grupos económicos transnacionales que continuaron hegemonizando el despliegue de actividades extractivas intensivas y tecnológicamente dependientes, a la vez que se logró imponer el establecimiento de una serie de mecanismos - derechos de exportación - que buscaron redistribuir la renta con el objetivo de alcanzar un desarrollo nacional con inclusión social, marcando así un giro relevante frente a la gestión anterior.

Contrariamente, la actividad hidrocarburífera no convencional introdujo, con el nuevo marco normativo elaborado para su implementación, un mayor control del Estado nacional para coordinar la acción de los actores privados y de los diferentes niveles del Estado bajo una estrategia nacional orientada al autoabastecimiento energético. Esta mayor participación del Estado implicó un avance en la toma de control sobre uno de los sectores claves para el desarrollo y sobre un bien estratégico, como los recursos energéticos en general y los hidrocarburos en particular. 
En cuanto al rol del Estado en la planificación y la producción del territorio, se incorporaron recursos e instancias dedicadas a la planificación, la gestión y el control de estas actividades que, en suma, incrementaron la participación estatal con la finalidad de direccionar el desarrollo con una visión más integral y revisar las disparidades entre regiones. Asimismo, al indagar en la cartera de proyectos formulados y concretados en materia de infraestructura, en los casos analizados se registró una prevalencia de la atención de necesidades para la producción, la circulación y la comercialización de commodities antes que la particularización en proyectos ligados a la lógica de reproducción social y económica de las comunidades locales.

En este sentido, se observó que las dinámicas de acumulación por desposesión heredadas de la década de 1990 y ligadas a los intereses corporativos de actores transnacionales permearon conflictivamente en la actuación de un Estado que, entre 2003 y 2015, buscó colocar un freno al avance de la hegemonía neoliberal. En ese contexto de inercias normativas internas y presiones externas, el Estado quedó atravesado por la tensión dada entre la resolución de las necesidades de las generaciones actuales y el sostenimiento de los ecosistemas para las generaciones futuras, punto nodal al analizar el devenir de los Estados en situación de dependencia como Argentina.

Finalmente, en el período analizado se observa cierta tensión entre los objetivos del Plan Estratégico Territorial ligados al logro de un territorio equilibrado y la actuación del Estado orientada a darle continuidad al (neo)extractivismo. De manera que esta continuidad implicó mantener vigentes estrategias globales de acumulación por desposesión, que se basa en la diferenciación territorial y el desarrollo geográfico desigual, hecho que se contrapone a los intentos por revertir la desigualdad territorial. En este punto, se vuelve necesario considerar las múltiples temporalidades (posiciones heredadas, urgencias presentes y expectativas) y las múltiples territorialidades que atraviesan críticamente a los países en condición de dependencia y tensionan su accionar. Asimismo, cabe preguntarse hasta qué punto el Estado, de forma autónoma, puede escindirse de la lógica de producción y acumulación predominante y, en ese sentido, si no es pertinente comprender las transformaciones políticas en torno a rol de Estado como microbatallas ganadas frente al avance de la razón neoliberal.

\section{Referencias}

Brenner, N. (2003). La formación de la ciudad global y el re-escalamiento del espacio del Estado en la Europa Occidental post-fordista. EURE, 29(86), 5-35.

Brenner, N., Peck, J., \& Theodore, N. (2015). Urbanismo neoliberal. La ciudad y el imperio de los mercados. En: Observatorio Metropolitano de Madrid (ed.), El mercado contra la ciudad. Globalización, gentrificación y politicas urbanas (pp. 211-243). Traficantes de Sueños.

Brenner, N. \& Theodore, N. (2017). Las ciudades y las geografias del neoliberalismo realmente existente. En: A. Sevilla Buitrago, Neil Brenner. Teoría urbana crítica y políticas de escala (pp. 113-159). Icaria.

Boletín Oficial de la República Argentina (2012). Ley 26.741, "Yacimientos Petrolíferos Fiscales". 7 de mayo de 2012, Buenos Aires, Secretaría Legal y Técnica de la Presidencia de la Nación Argentina. http://servicios.infoleg.gob. ar/infolegInternet/anexos/195000-199999/196894/ norma.htm

Bolsa de Comercio de Rosario (BCR) (2015). Informativo Semanal, $\mathrm{n}^{\circ}$ 1718. https://www.bcr.com.ar/sites/default/files/2019-05/bcr2015_07_31.pdf

Delgado Ramos, G. C. (2010). América Latina y el Caribe como reservas estratégicas de minerales. En: G. G. Delgado Ramos (coord.), Ecología política de la minería en América Latina. Aspectos socioeconómicos, legales y ambientales de la megaminería (pp. 17-58). Centro de Investigaciones Interdisciplinarias en Ciencias y Humanidades; Universidad Nacional Autónoma de México.

Dirección Nacional de Inversión Pública, Jefatura de Gabinete de Ministros (2021). Banco de Proyectos de Inversión Pública (BAPIN). https://www.argentina.gob. ar/dnip/bapin

González Sousa, R. (2014). América Latina ante el desarrollo territorial sostenible: retos e incertidumbres en un mundo globalizado. Perspectiva Geográfica, 18(1), 91116. https://doi.org/10.19053/01233769.2251 
Gudynas, E. (2017). Extractivismos y corrupción en América del Sur: estructuras, dinámicas y tendencias en una íntima relación. ReviISE, 10(10), 73-87.

Haesbaert, R. (2011). El mito de la desterritorialización: del "fin de los territorios" a la multiterritorialidad. Siglo xxI.

Harvey, D. (2005). El "nuevo" imperialismo: Acumulación por desposesión. En: L. Panitch \& C. Layes (eds.), Socialist register 2004 (pp. 99-129). Clacso.

Instituto Argentino del Petróleo y del Gas (IAPG) (2015). EPG Argentina Anuario 2015. Serie Estadísticas de Petróleo y Gas (EPG). IAPG.

Instituto Nacional de Estadística y Censos de la República Argentina (INDEC), Dirección Nacional de Estadísticas del Sector Externo (2020). Origen provincial de las exportaciones, por provincia y principales grandes rubros, en millones de dólares. Años 1993-2020. https://www.indec.gob.ar/indec/web/Nivel4-Tema-3-2-79

Laval, C. \& Dardot, P. (2013) La nueva razón del mundo. Ensayo sobre la sociedad neoliberal. Gedisa.

Ministerio de Economía de Argentina, Secretaría de Política Económica, Subsecretaría de Programación Regional y Sectorial (2020). Neuquén, Informe Productivo Provincial. https://www.argentina.gob.ar/sites/default/ files/informe_productivo_neuquen_12-2020.pdf

Ministerio de Hacienda y Finanzas Públicas de la Nación (2016). Informes productivos provinciales: Chaco, año $1, \mathrm{n}^{\circ} 6$.

Ministerio de Planificación Federal, Inversión Pública y Servicios (MINPLAN) (2004a). Plan Energético Nacional 2004-2008.

Ministerio de Planificación Federal, Inversión Pública y Servicios (MINPLAN) (2004b). Plan Minero Nacional.
Ministerio de Planificación Federal, Inversión Pública y Servicios (MinPlan) (2008). Plan Estratégico Territorial PET. Avance 2008.

Ministerio de Planificación Federal, Inversión Pública y Servicios (MINPLAN) (2011). Plan Estratégico Territorial PET. Avance II.

Ministerio de Planificación Federal, Inversión Pública y Servicios (MINPLAN) (2015). Plan Estratégico Territorial PET. Avance III.

Morina, J. O. \& Cacace, G. (2017). Geografias extractivistas en la Argentina de los bicentenarios. Revista del Departamento de Ciencias Sociales, Universidad Nacional de Luján, 4(5), 03-18.

Peck, J. \& Theodore, N. (2019). Still Neoliberalism? The South Atlantic Quarterly, 118(2), 245-265. https://doi. org/10.1215/00382876-7381122

Schweitzer, M., Carrizo, S., Scardino, M., Petrocelli, S. P., Schweitzer, P., \& Carena, M. L. (2017). Planificación en Argentina a principios del siglo xxi. Revista Área, 23, 25-35.

Secretaría de Biblioteca y Jurisprudencia del Poder Judicial (2010). Compre Neuquino, Ley 2.755/2010, 14 de diciembre de 2010, Neuquén, Poder Judicial de Neuquén. http://200.70.33.130/index.php/normativas-provinciales/leyes-provinciales/1416

Sociedad Nacional de Minería de Chile (2021). Estadísticas de precios. https://www.sonami.cl/v2/informacion-de-la-mineria/estadisticas-de-precios/

Tzeiman, A. (2021). La fobia al Estado en América Latina: reflexiones teórico-políticas sobre la dependencia y el desarrollo. Clacso; Instituto de Investigaciones Gino Germani. 